Research Article

\title{
Improvement of the Acoustic Attenuation of Plaster Composites by the Addition of Short-Fibre Reinforcement
}

\author{
P. Kulhavý $\mathbb{D},{ }^{1}$ A. Samková $\left(\mathbb{D},{ }^{2}\right.$ M. Petru $\mathbb{D}^{1},{ }^{1}$ and M. Pechociakova ${ }^{2}{ }^{2}$ \\ ${ }^{1}$ Institute for Nanomaterials, Advanced Technologies and Innovation, Technical University of Liberec, Studentska 2, \\ 461 17, Liberec, Czech Republic \\ ${ }^{2}$ Faculty of Textile Engineering, Technical University of Liberec, Studentska 2, 461 17, Liberec, Czech Republic
}

Correspondence should be addressed to P. Kulhavý; petr.kulhavy@tul.cz

Received 5 January 2018; Revised 31 March 2018; Accepted 16 April 2018; Published 16 May 2018

Academic Editor: Bing Zhang

Copyright (c) 2018 P. Kulhavý et al. This is an open access article distributed under the Creative Commons Attribution License, which permits unrestricted use, distribution, and reproduction in any medium, provided the original work is properly cited.

\begin{abstract}
Noise attenuation is a key contemporary issue associated with the protection of human health. In this study, the possibilities of affecting acoustic properties of plaster composites by the addition of short-fibre reinforcement are described. The improvement of attenuation abilities was first verified using a simple numerical model with a pure plaster followed by using a reinforced plaster. The model results revealed a mutual correlation between the fibre ratio and dissipated acoustic energy. Hence, typical plasters used in the building industry (e.g., plaster, lime cement, and cement) are used as the base materials of the tested composites. The reinforcing dispersion in the form of short fibres (basalt and glass) with a defined length was selected after evidence from previously reported studies and after the comparison of some other fibres with respect to the trade-off between the rendered mechanical properties and cost. Transfer functions of the tested samples were measured using an impedance tube with two microphones, followed by the calculation of the total acoustic absorption. On the other hand, cement and plaster materials exhibited a low damping ability, and the absorption could be considerably increased by the addition of fibres, especially in the area around $1 \mathrm{kHz}$. In contrast, the UM plaster exhibited good damping properties even without the dispersion, and the addition of improper fibres such as glass ones possibly worsened the properties. The acoustic attenuation of the plaster composites can be improved by the appropriate combination of the base material and fibre dispersion. However, it is not possible to generalise this improvement for all possible combinations.
\end{abstract}

\section{Introduction}

Currently, the enormous technological development could be observed in a lot of everyday life sectors such as transport and other industries. In addition, this phenomenon exerts some negative effects, one of them being the increasing noise levels. The increase in industrialisation and transport technologies has led to a rapidly increasing number of people being affected by residing in an extremely noisy environment. Several detailed physiological and hygienic studies have revealed that noise is one of the most widespread harmful factors not only in workplaces, but also in everyday life [1]. Long-term, frequent exposure to noise affect not only the mental state (e.g., tiredness or concentration ability), but also the overall health of the human beings, as well as cause some irreversible harm. Hence, it is crucial to protect human beings by decreasing noise levels $[1,2]$. Issues associated with noise in such environments are constantly increasing; therefore, common people, employers, and employees require their homes and working places to be protected [3]. Requirements related to this issue are reflected in the directives and regulations, and the $\mathrm{Eu}-$ ropean Union also recognises environmental noise as one of the most important environmental issues. Because of this fact, laws regulating noise levels are valid in several countries [4]. Noise reduction should be conceptually solved with regard to the interactive approach, especially with respect to the noise source and its surroundings. Despite the fact that passive measures, such as wall cladding panels with porous materials and resonators, address only the consequences but 
not the main causes of noise, these factors are often the only possible and viable solution. The ability of building materials to absorb sound waves typically depends on their stiffness, density, and porosity [5-7]. The function of the absorption coefficient exists in order to quantify the ability of materials to absorb sound waves at a specific frequency. When sound reaches a specific part, it dissipates, passes through, or reflects depending on the physical properties and microstructure of materials [8]. Therefore, parts such as walls and roofs of buildings, which constitute the main parts of a residential or industrial object require materials with a high absorption coefficient such as wool glass, foam, mineral wools, or their composites [9]. Currently, various products such as chopped fibres, grids, steel truss, rovings, and veils can improve the mechanical and acoustic properties of the main building materials. Pedreño-Rojas et al. have added some recycled wood to the gypsum matrix [10]. Their experiments revealed that by increasing the percentage of the added wood waste, the mass of the new material decreases while simultaneously improving its thermal and sound absorption properties. Their group has revealed that the best results (with respect to the acoustic and mechanical properties) are achieved by the addition of up to $10 \%-20 \%$ of wood shavings or sawdust composites.

Generally, the mechanical and physical properties of typically used construction materials (fired and silicate bricks, bricks, concrete, aerated concrete, steel-reinforced concrete, glass wool, and polystyrene) have been extensively investigated. However, the materials used in this sector are often produced from nonrenewable natural resources, and the production of these materials adversely affects the environment $[11,12]$. Hence, in recent years, increased efforts to use materials, including some typical natural materials such as flax, hemp, wood, straw, reeds, and others that can reduce the negative impact on the environment have been observed. Typically, flax and hemp fibres are used to insulate buildings. Wood and wood sawdust can be used on walls and as a filler for building materials, respectively. Another wellknown conventional method is to use reed bundles as roofing and straw in combination with clay for wall filling and reinforcement [13]. Randazzo et al. [14] have tested some commercially available clay plasters typically used in Europe for exploring the manner in which mineralogical and textural properties can affect their physical parameters; that is moisture absorption, thermal conductivity, and noise attenuation. Results obtained from the tests revealed that the addition of natural fibres slightly increases the open porosity; hence, because of its relatively higher pore volume, the obtained final sound absorption is possibly higher.

Porosity considerably affected the material's ability to absorb sound waves. The principle is mainly caused by different resistivities of individual materials (such as solid and air) and phenomena occurring at their mutual interfaces. Generally, several routes of energy dissipation simultaneously occur, that is, reflection at the boundaries, deflection caused by different speeds of sound propagation in individual materials, and friction of air on the walls in micropores. Pore size can be categorised at different scales (i.e., micropores, interparticle pores, and mesopores). Cannabis

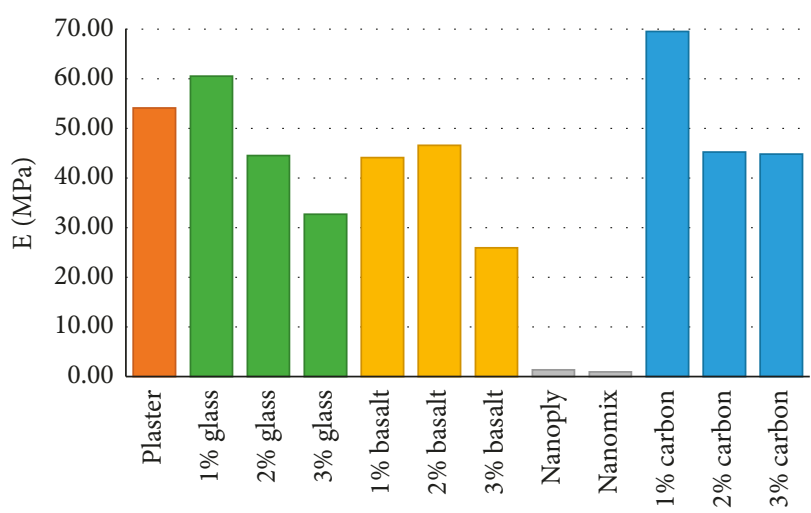

FIgURE 1: Comparison of Young's modulus of the Thermo UM lime-cement plaster with various types of reinforcement.

and lime-based composites exhibit one of the highest porosities (70\%-80\%) [15]. Gle et al. [16] have extensively examined the acoustic benefits observed with the use of cannabis composites. This study revealed that the level of sound absorption in hemp-reinforced concrete can be controlled and significantly increased using suitable components with specified manufacturing processes.

As has been previously mentioned, fibrous materials are typically added to building materials as a reinforcing element to modify their mechanical properties, such as tensile strength, compressive strength, or impact strength. Previous studies [17] have reported significant improvement in the main mechanical properties of plaster composites by the addition of an appropriate volume ratio of fibres $(1 \%-2 \%$ of reinforcement). Glass and basalt fibres were used as the reinforcing elements. Similar issues have been reported by Blankenhorn and Soroushian $[18,19]$ with focus on cellulosecement composites. Neithalath et al. [20] have investigated the effects of natural fibre reinforcement to the morphological changes in acoustic and mechanical properties. The results obtained from their study clearly revealed the increasing dependence of the acoustic absorption coefficient on the fibre volume. In other independent studies reported by Kalinova and Mohrova [21, 22], the use of nanofiber structures as sound-absorbing elements and nanomembranes as resonators has been described.

Experimental studies have reported improvement in the acoustic, thermal, and mechanical properties of plasters by the addition of short-fibre cellulose [20, 23] or polypropylene [24] as reinforcement. However, according to [24], the improvement of the aforementioned properties by fiber count is questionable.

This study focuses on the sound attenuation characteristics in plaster composites. Three typical plasters (viz., gypsum, lime cement, and cement, resp.) were reinforced with glass and basalt fibres, and impedance tube measurements were carried out.

\section{Materials and Methods}

Typical plaster and cement plaster were completed with limecement plaster that exhibits enhanced thermoinsulating 
TABLE 1: Mechanical properties of the base materials.

\begin{tabular}{|c|c|c|c|c|c|}
\hline Material & Length $(\mathrm{mm})$ & Diameter $(\mu \mathrm{m})$ & Density $\left(\mathrm{kg} \mathrm{m}^{-3}\right)$ & $\mathrm{E}(\mathrm{GPa})$ & $\mu(-)$ \\
\hline Basalt fibre & 7.7 & 13 & 2650 & 110 & 0.26 \\
\hline Glass fibre & 12 & 14 & 2600 & 76 & 0.22 \\
\hline Thermo UM & - & - & 551 & 5.4 & 0.18 \\
\hline Gypsum & - & - & 1100 & 14 & 0.27 \\
\hline Cement & - & - & 3020 & 39 & 0.2 \\
\hline
\end{tabular}

properties (Thermo UM); these plaster materials are typically suitable for the central European climate, which can be possibly prepared even under laboratory conditions, without the requirement of any specific machinery. Furthermore, plasters such as gravel, perlite, mineral, or stucco plaster are also available in the market. Flass, carbon, basalt fibres, and even some nanofibrous dispersions were used as reinforcing elements for composites. In previously reported papers by the authors of this study [17], all possible combinations of typical plasters and fibre reinforcements have been investigated with respect to their mechanical properties (Figure 1). The results revealed that when using a suitable mass ratio $(1 \%-2 \%$ of fibre reinforcement), the mechanical properties (flexural or tensile strength, compressive strength, and impact strength) of the plaster composites possibly improved significantly [17]. Based on those results, three plasters and two fibre reinforcement materials, the mechanical properties of which can be improved, or at least not worsened, were selected for their acoustic attenuation. Although the carbon fibres should be considered on the basis of the obtained mechanical properties, the fibres were not included for additional tests because the cost of the dispersion was greater than that of the base plaster material. Table 1 summarises the fundamental mechanical properties of the base materials.

Similar to that carried out during the initial verification of the model, the pure plaster without any fibre dispersion was investigated. The second set of samples contained $7.7 \mathrm{~mm}$-long basalt fibres with a diameter of $13 \mu \mathrm{m}$. The final sets were created from alkalised glass fibre with a length of $12 \mathrm{~mm}$ and a diameter of $14 \mu \mathrm{m}$. The fibre length was selected on the basis of the determined critical length of the individual types of fibre dispersion [25].

2.1. Basic Theory for the Study of Acoustic Quantities. The mechanical oscillation of liquid, solid, or gas particles spread as waves called sound, which is always connected to energy transfer. Pressure oscillations in the surroundings, typically gaseous environment, can produce acoustic field or just generally the sound. These pressure changes are caused by the oscillation of the cover surfaces of individual parts or entire systems. When considering noise in a structure, subjective noise perception must be considered, particularly in an urban environment [26]. Sound field is described by changes in steady-state variables, such as pressure, speed, temperature, and density, which describes the state of the environment in which sound spreads. The actual sound velocity $c$, which depends on the modulus of elasticity $E$ and the density of the material $\rho$, is determined by the spreading velocity of the longitudinal waves in an unbounded space according to (1). Energy dissipation occurs because of the absorption of sound by the material; therefore, the velocity potential $\varphi$, where the velocity is equal to the negative velocity gradient (2), could be introduced. The speed potential permits the definition of sound pressure $p$ according to (3). The specific mechanical impedance $Z$ (4) can be used to quantify the sound transfer between the two materials as the ratio of the passing and impacting energy. To understand the basics of sound propagation and attenuation, it is possible to use the basic assumptions that can be well characterised by a simplified 1D structure as mentioned in references [26, 27]. Considering a 1D structure in which some planar or longitudinal wave spreads, this phenomenon is associated with structural deformation. Then, the ratio between the passing energy and the incident energy can be expressed as the ratio between the through and incident wave intensities, according to (5). Based on this assumption, transfer attenuation (6) can be defined using the transfer coefficient (5). An example involves the steel-aluminium combination when it is possible to obtain a transmission attenuation coefficient of only $1.6 \mathrm{~dB}$. On the other hand, for steel PVC, the attenuation could reach up to $14 \mathrm{~dB}$ [26]. By simplifying the problem according to (5) and (6) where some factors of the acoustic system were neglected, it is possible to obtain the corresponding mathematical expression that can be used to optimise the intensity of the passing waves.

$$
\begin{aligned}
& c=\sqrt{\frac{E}{\rho}}, \\
& c=-\nabla \phi, \\
& p=\rho\left[\frac{\partial \phi}{\partial t}-\frac{1}{2}\left(\frac{\partial \phi}{\partial x}\right)^{2}\right], \\
& Z=\rho \cdot c, \\
& d=\frac{4 Z_{i} Z_{j}}{\left(Z_{i}+Z_{j}\right)^{2}}, \\
& D=10 \log \frac{1}{d},
\end{aligned}
$$

where $Z_{i}$ and $Z_{j}$ represent $i$ and $j$-materials, respectively.

The final attenuation is attributed to the combination of different damping properties of individual materials. Therefore, for modelling and describing the attenuation, it is crucial to introduce the complex dynamic modulus $\widetilde{E}(7)$, where the inner damping coefficient $\eta$ of materials can be 
TABLe 2: Typical physical properties of typical materials [26, 27].

\begin{tabular}{lccccc}
\hline Material & Density $\left(\mathrm{kg} \mathrm{m}^{-3}\right)$ & $\mathrm{E}(\mathrm{Pa})$ & $\mathrm{c}\left(\mathrm{m} \mathrm{s} \mathrm{s}^{-1}\right)$ & $\mathrm{Z}\left(\mathrm{N} \cdot \mathrm{s} \cdot \mathrm{m}^{-3}\right)$ & $4.14 \times 10^{2}$ \\
\hline Air & 1.21 & - & 344 & $7.3 \times 10^{4}$ & \multicolumn{1}{c}{ Absorption $(-)$} \\
Rubber & 900 & $4.4 \times 10^{4}$ & 70 & $7.1 \times 10^{6}$ & $0.02-1$ \\
Concrete & 2300 & $1.0 \times 10^{10}$ & 3100 & $1.6 \times 10^{6}$ & 0.007 \\
Aerated concrete & 900 & $2.9 \times 10^{9}$ & 1800 & $5.6 \times 10^{6}$ & $0.005-0.012$ \\
Bricks & 2000 & $1.6 \times 10^{10}$ & 2800 & $2.5 \times 10^{6}$ & $0.009-0.1$ \\
Wood & 650 & $1.0 \times 10^{10}$ & 3900 & $1.3 \times 10^{7}$ & 0.015 \\
Aluminium & 2700 & $6.2 \times 10^{10}$ & 4800 & $4.5 \times 10^{7}$ & $7.1 \times 10^{-10}$ \\
Steel & 7850 & $2.6 \times 10^{11}$ & 5750 & $1.1 \times 10^{-4}$ \\
\hline
\end{tabular}

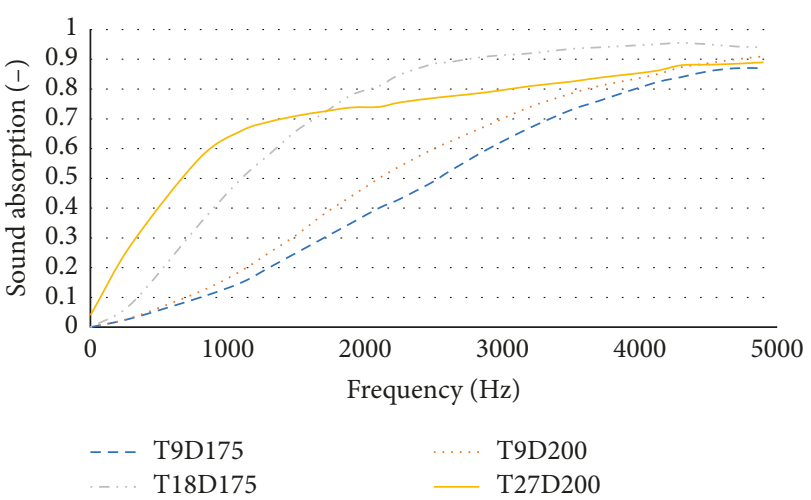

Figure 2: Results from the absorption coefficient of basalt layers from the study by Moretti et al. [30].

defined by relation (8). Table 2 summarises the internal damping coefficients of several selected materials. Extremely dense materials that reflect $100 \%$ sound exhibit a sound absorption coefficient equal to 0 [28].

$$
\begin{aligned}
& \widetilde{E}=E(1+i \eta), \\
& \eta=\frac{I_{m}\{\widetilde{E}\}}{R_{e}\{\widetilde{E}\}},
\end{aligned}
$$

The sound absorption of plasters at a frequency of $1000 \mathrm{~Hz}$ is $0.02-0.05$ [29]. The absorption coefficient of the fibrous layers is affected by the thickness and density of these layers. Moretti et al. [30] have tested basalt layers of different thicknesses and densities. From the results obtained (Figure 2), fibrous layers exhibit an extremely good absorption coefficient, especially at high frequencies. Figure 2 shows sound absorption properties for some chosen fibres with a layer thickness Tof 9, 18, and $27 \mathrm{~mm}$ and densities D of 175 and $200 \mathrm{~kg} \cdot \mathrm{m}^{-3}$, which is taken from the study by Moretti et al. [30]. In particular, at low frequencies, sound absorption depends on the fibre thickness.

Wang and Torng have also carried out a similar study [31] in which the absorption characteristics of porous materials reinforced with glass and basalt fibres were investigated. The $50 \mathrm{~mm}$-thick glass fibre layer with a bulk density of $100 \mathrm{~kg} \cdot \mathrm{m}^{-3}$ exhibits an absorption coefficient of 0.82 . The basalt layer with the same thickness and bulk density exhibits an absorption coefficient of 0.9 . Their results revealed that both fibres exhibit similar sound absorption.
2.2. Plaster. Plasters are mainly categorised according to the binder used. The binder ensures adhesion to the masonry as well as plaster strength and durability (the ability to withstand environmental impacts). The plaster is formed after hardening of the mortar mixture.

The first of the plasters selected herein was lime cement with enhanced thermal insulation properties, that is, Thermo UM. Another significant feature of this material is low bulk density compared to typically used plasters: This plaster is 4 times lighter. Because of its low bulk density and low modulus of elasticity, the plaster eliminates volume or shape changes in the base wall material, thereby not creating any cracks. Thermo UM plaster is characterised by a high thermal conductivity coefficient and the plaster's chemical composition eliminates microbial, algal, and fungal growth on its surface [32].

Another plaster, referred to as gypsum plaster, is a typically cheaper material. It exhibits good thermal insulation and acoustic attenuation. Owing to its thermal properties, the plaster is thought to be a hygroscopic material, which permits the regulation of the room microclimate $[33,34]$. Vapour can permeate into the plaster and does not close the water in the construction while simultaneously permitting the natural drying of residual water from the blocks. Gypsum plaster is suitable for antibacterial environment because its smooth surface prevents dust from settling on it. At high temperatures, water vapour is released by gypsum, which is typically used to increase fire resistance [35].

The last plaster, which is referred to as cement plaster, is designed for highly loaded areas; it exhibits increased strength, water resistance, and adhesion to the base substrate, as well as frost and weather resistance.

2.3. Fibre Types and Proportion. In this study, short glass and basalt fibres were used as dispersion elements. Such fibres are typically used in the building industry particularly because of the cost-effectiveness as well as acoustic and thermal insulation properties.

Basalt is typically formed by decompression melting in the Earth's upper mantle. This rock is made up of different species such as pyroxene, magnetite, olivine, and plagioclase [36]. The basic technological condition for selecting optimal kind of basalt for producing fibres is the so-called acidity factor $M_{k}(9)$. Militky [37] has reported that the acidity factor ranges from 1.1 to 3 . The most appropriate technological condition for producing fibres is at $M_{k}=1.65$. 


$$
M_{k}=\frac{\mathrm{SiO}_{2}+\mathrm{Al}_{2} \mathrm{O}_{3}}{\mathrm{CaO}+\mathrm{MgO}} .
$$

The selection of basalt rocks for producing fibres is affected not only by the chemical and mineralogical composition, but also by the rock texture [38]. The resulting quality of fibres is affected by the level of technological equipment and the entire technological production process. Moretti et al. [30] have developed a mineral fibre acoustic absorption panel for a highly efficient power system in buildings. The results of their application revealed extremely good acoustic and thermal properties for these panels. The additional advantage is chemical stability, low thickness, and considerable mechanical strength.

Compared to glass, basalt fibres are more stable in a strongly alkaline environment, but in a strongly acidic environment, the fibres exhibit lower stability [39]. The glass fibre base comprises tetrahedrons $\left(\mathrm{SiO}_{4}\right)^{4-}$ and contains different oxides. The individual types of glass fibres can be distributed according to their oxide content. For producing fibres, not only glass stones, but also different processed glass metaproducts such as glass beads, rods, frits, or waste glass shards were used. The base glass composition significantly affects the properties of the resulting fibres [40].

One of the most frequently declared fibre parameters is their linear mass density $t(10)$ :

$$
t[\text { tex }]=\frac{m}{l}=\frac{s l \rho}{l}=s \rho,
$$

where $m$ is the mass $(\mathrm{g}), l$ is the length $(\mathrm{km}), s$ is equivalent to the fibre diameter $(\mu \mathrm{m})$, and $\rho$ is the fibre density $\left(\mathrm{kg} / \mathrm{m}^{3}\right)$.

The $d$ value can also be calculated according to (11) for noncircular cross sections. Then, $d$ is called the equivalent fibre diameter.

$$
d=\sqrt{\frac{4 S}{\pi}}=\sqrt{\frac{4 t}{\pi \rho}} .
$$

2.4. Porosity. With respect to the sound attenuation and thermal insulation purposes, the porosity of the resulting part of the fibre-filled materials is crucial compared to the basic physical properties. The porosity $\psi(12)$ represents the proportion of the fibre structure that is filled with air. As has been already mentioned, the sound absorption mechanism depends on the amount and mutual bonding of the pores inside the material. Good sound-absorbing materials contain interconnected pores, which enable further sound propagation and permit air flow under acoustic oscillation. Hence, the first principle of acoustic energy dissipation caused by friction is used. To express pore volume, an analogy based on the determination of porosity in thick nonwoven formations has been used. This idea could be valid on the basis of the assumption [41] that the fibre surface is approximately equal to the pore surface. This method is probably not the most suitable one, and direct measurement based on some screening methods can be used to possibly set statistically more precise results, but only to estimate porosity, sufficiently precise results should be obtained:

$$
\psi=\frac{V_{\mathrm{c}}-V-V_{\mathrm{p}}}{V_{\mathrm{c}}},
$$

where $V_{\mathrm{c}}$ is the total volume of the body, $V_{\mathrm{p}}$ is the pore volume, and $V$ is the fibre volume.

As the same volume of air may be found in a few large pores or in a number of small pores, the median pore size $\xi$ is determined:

$$
\xi=\frac{V_{\mathrm{p}}}{A_{\mathrm{p}}},
$$

where $A_{\mathrm{p}}$ is the pore area.

$V_{\mathrm{p}}$ (or simply the air volume) in fibre formation can be calculated as follows:

$$
V_{\mathrm{p}}=V_{\mathrm{c}}-V
$$

An important prerequisite according to reference [41] is that where the fibre ends, the air around it begins. Thus, the fibre surface is also the pore surface. Based on this assumption, the pore surface $A_{\mathrm{p}}$ can be obtained from

$$
A_{\mathrm{p}}=A=L \times p \text {, }
$$

where $A$ is the fibre surface, $L$ is the total length of all fibres in the fibrous structure, and $p$ is the cross-sectional circumference of the fibre.

The shape of the interfacial pores is complicated; hence, the interfibrous pores are considered to be shaped as capillaries. The pores can be imagined as air fibres, and then their surface can be calculated as follows:

$$
A_{\mathrm{p}}=L_{\mathrm{p}} \pi d_{\mathrm{p}}\left(1+q_{\mathrm{p}}\right) \text {, }
$$

where $L_{\mathrm{p}}$ is the length of the pore capillaries in the fibrous form, $d_{\mathrm{p}}$ is the equivalent pore diameter, and $q_{\mathrm{p}}$ is the pore shape factor, which is defined as

$$
q_{\mathrm{p}}=\frac{p}{\pi d_{\mathrm{p}}}-1
$$

Because the geometric characteristics $\xi$ (13) depend on the pore shape, it is possible to use the simple assumption that the shape of the pores is still the same. Therefore, for the pore shape factor, it is possible to set $q_{\mathrm{p}}=$ constant and fibre shape factor $q=$ constant and hence

$$
\frac{1+q_{\mathrm{p}}}{1+q}=k
$$

Subsequently, pore volume (19) can then be expressed as follows:

$$
V_{\mathrm{p}}=\frac{\pi d_{\mathrm{p}}^{2}}{4} L_{\mathrm{p}}
$$

Figure 3 shows the ratio of pores in the studied samples determined by the aforementioned method. 


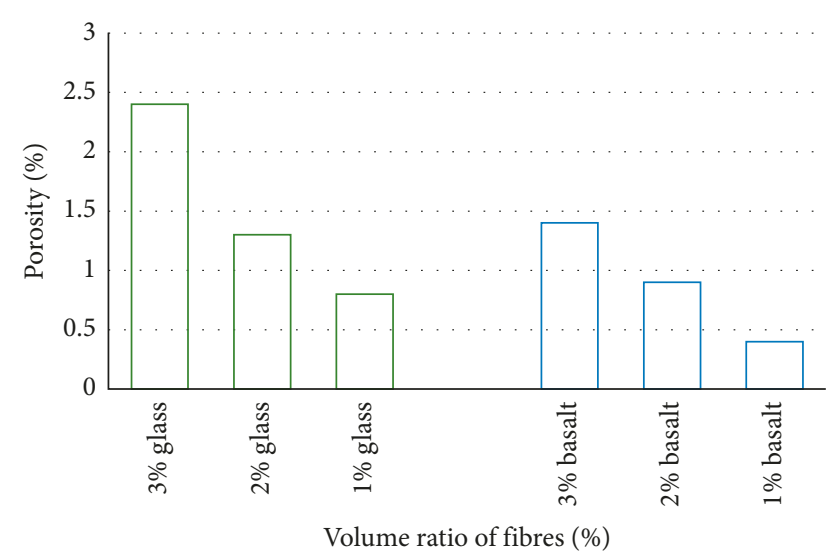

FIgUre 3: Porosity of materials with the specified fibre volume ratio.

2.5. Sample Preparation and Testing. Typically, 6\% of the fibre reinforcement is used in concrete materials. However, blending the plaster and fibres with such a high content can cause some problems in their bonding. The fibre reinforcement content in this experiment was 1\% (Figure 3 and Table 3) because the optimal improvement of mechanical properties as has been reported in a previous study in which the glass and basalt filaments were used as the reinforcing elements was observed at weight ratios of $1 \%$, $2 \%$, and $3 \%$ [17]. The calculation of the mixing ratio (20) is based on the percentage of the components in the composite and their densities:

$$
w_{i}=\frac{V_{i} \cdot \rho_{i}}{\sum V_{i} \rho_{i}},
$$

where $w_{i}(\%)$ is the mass fraction of the $i$ th component, $V_{i}$ (\%) is the volume fraction of the $i$ th component, and $\rho_{i}$ $\left(\mathrm{kg} \cdot \mathrm{m}^{-3}\right)$ is the density of the $i$ th component.

Experimental samples (Figure 4) were created in circular releasable moulds with a diameter $99.8 \mathrm{~mm}$ (required for an impedance tube inner diameter of $100 \mathrm{~mm}$ at the tolerance field K7) and a thickness of $10 \mathrm{~mm}$.

Figure 5 shows the microscopic pictures of all combinations of plaster and fibre. The legend of Table 4 provides an overview of the photograph and material combination.

2.6. Experimental Measurement and Modelling. Basically, the improvement of the acoustic absorption was first verified by the addition of fibres using a simple numerical model simulating the passage of sound waves through the plaster as well as fibre-reinforced plaster. Even if the first simplified model of inner porosity and all necessary mechanical properties were not precise, the simulation revealed that the principle should work in theory. This is a model of acoustic absorption using a porous acoustic open cell sample. In porous materials, sound propagates in a network of small interconnected pores. Because of small pore dimensions, losses occur particularly because of thermal conduction and viscous friction. This model aims to characterise the absorption properties, more specifically, the specific surface
TABLE 3: Volume fraction of the individual components.

\begin{tabular}{lcc}
\hline $\begin{array}{l}\text { Volume } \\
\text { fraction, } V_{i} 1 \%\end{array}$ & $\begin{array}{c}\text { Mass fraction } \\
(\%) \text { of glass fibres }\end{array}$ & Basalt fibres \\
\hline Thermo UM & 4.38 & 5.05 \\
Gypsum & 2.15 & 2.49 \\
Cement & 0.83 & 0.96 \\
\hline
\end{tabular}

impedance and absorption coefficient in terms of sound incidence angle and frequency. The model uses a $2 \mathrm{D}$ geometry of such a system. The models were created in COMSOL. Base models of the samples (plaster Thermo UM, gypsum, and cement) were created using the Pressure Acoustics user interface with a rigid Biot equivalent fluid model $[42,43]$. The surrounding fluid is air, and the incident pressure $p_{\text {inp }}$ is expressed as shown in the following equation:

$$
\begin{aligned}
p_{\text {inp }} & =e^{-i(k x)} ; \\
k & =k_{0}(\sin \theta, \cos \theta),
\end{aligned}
$$

where $\theta$ and $k_{0}$ are the incidence angle and wavenumber in the free field (air domain), respectively. The pressure $p$ solved in this model is the total field, and the scattered field $p_{\text {scat }}$ is expressed as $p_{\text {scat }}=p-p_{\text {inp }}$. Notably, this expression for the scattered field is only valid in the air domain as the incident field is not known apriori for porous materials. Two parameters that characterise the absorption properties of the porous absorber are the specific surface impedance $Z$ and the absorption coefficient $\alpha$ (Table 1). The absorption coefficient, which represents the ratio of the absorbed and incident energy, is defined as follows:

$$
\begin{aligned}
& \alpha=1-|R|^{2} \\
& R=\frac{p_{\text {scat }}}{p_{\text {inp }}}
\end{aligned}
$$

where $R$ is the pressure reflection coefficient that expresses the ratio of the scattered to the incident pressure.

Subsequently, geometric dimensions (sample diameter $D=100 \mathrm{~mm}$ and sample thickness $=10 \mathrm{~mm}$ ) and material properties of the sample were determined and maintained constant (porosity, speed of sound, dynamic viscosity, thermal conductivity, and density). The modelled frequencies range from $100 \mathrm{~Hz}$ to $1.2 \mathrm{kHz}$ at a minimal wavelength of $0.0344 \mathrm{~m}$, and the absolute pressure is 1 bar. Figure 6 shows the layout of the modelled domain. An approach similar to the boundary conditions has been used according to the study reported by Cox and Antonio [44]. For investigating the acoustic absorption, it is crucial to prepare samples with a precise cylindrical profile such that they can accurately fit into the clamping part of the impedance tube. As mentioned previously, three plasters (i.e., gypsum, cement and lime, resp.) and two fibres (i.e., glass and basalt, resp.) have been tested. Based on the basic characteristics of the individual materials, the best results for acoustic absorption can be assumed to be achieved using basalt-fibre-reinforced 


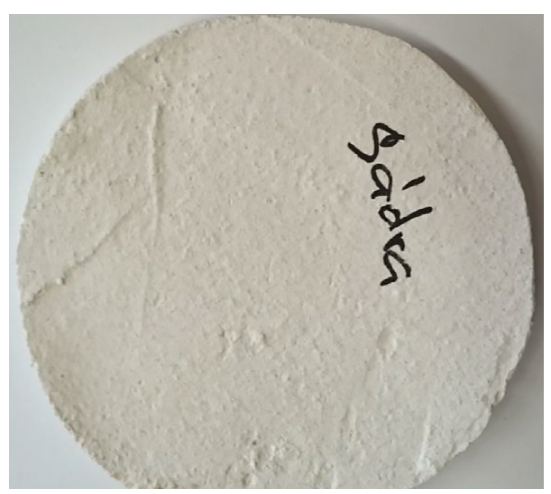

(a)



(b)

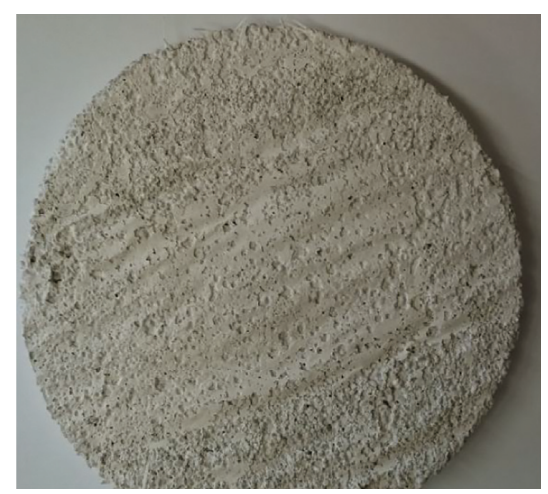

(c)

Figure 4: Tested samples: (a) gypsum, (b) cement with glass fibre, and (c) lime cement.

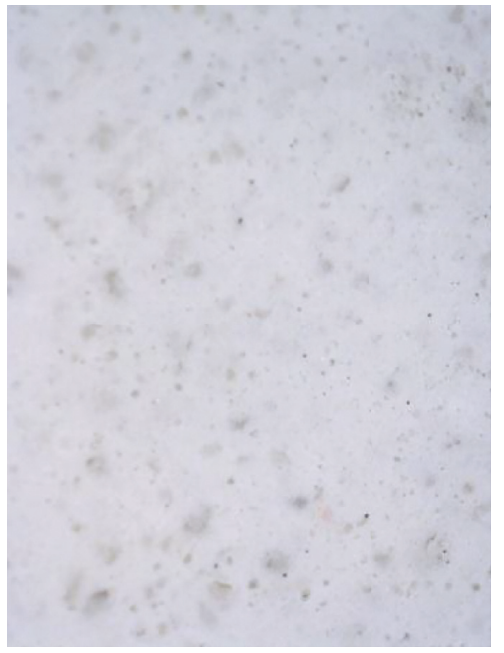

(a)

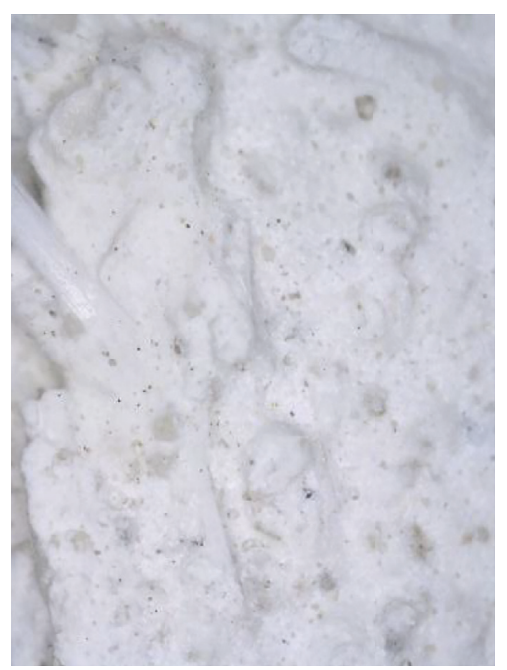

(d)

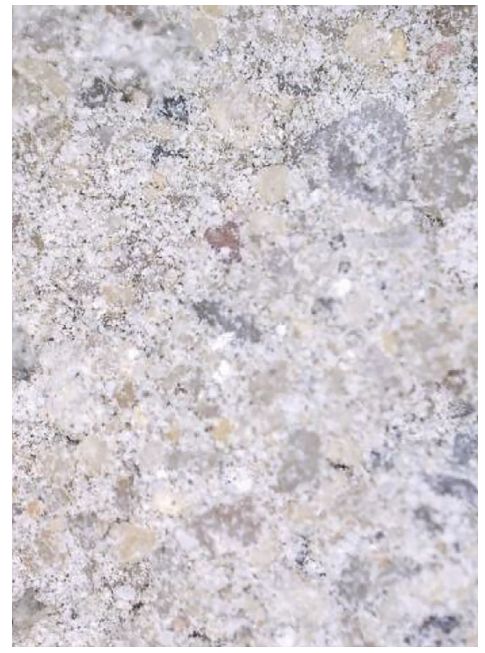

(b)



(e)

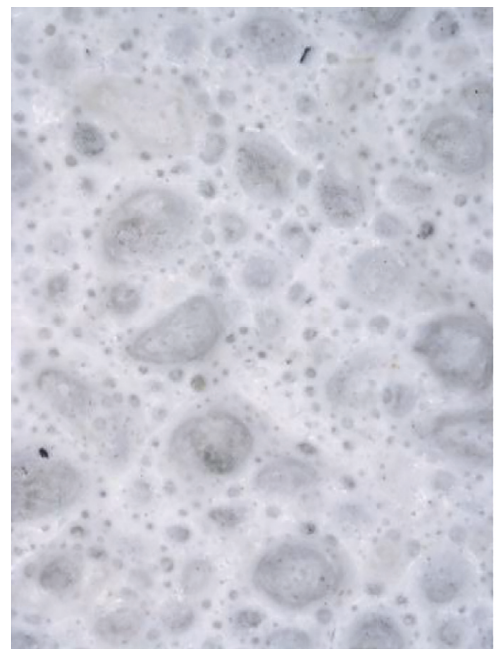

(c)

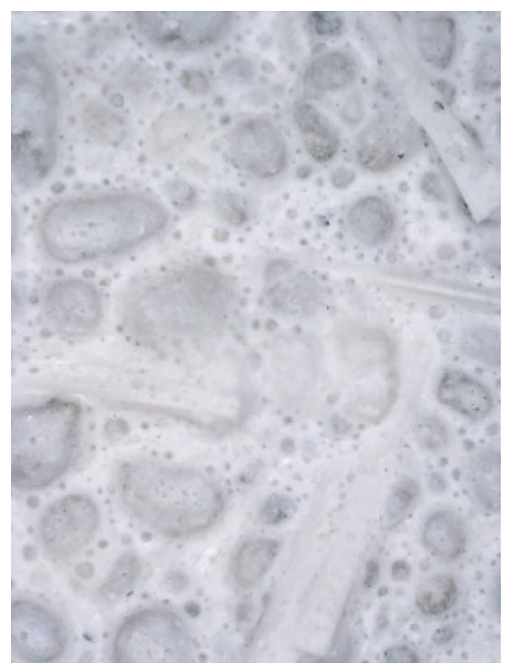

(f)

Figure 5: Continued. 


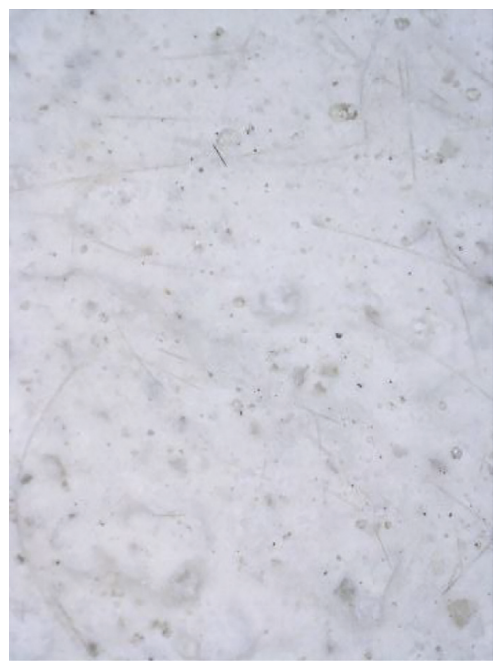

(g)



(h)

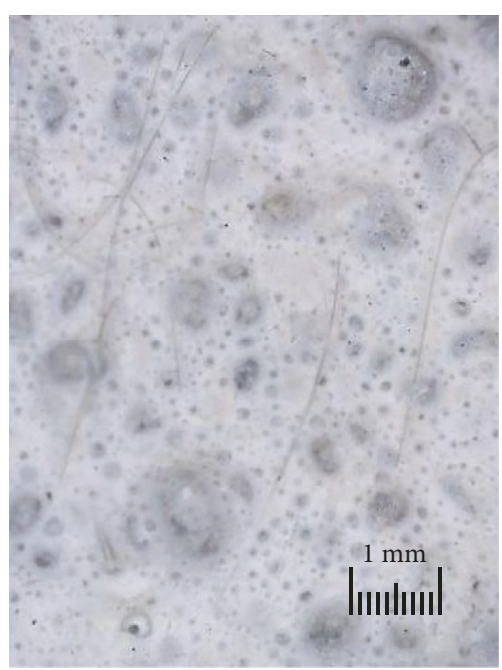

(i)

FigURE 5: Microstructure of all tested samples and scale used in micrometres.

lime cement according to the study by Wang and Torng [31]. The reason for this assumption was that hollow silicate beads were present inside the mixture of lime-cement plaster, which basically serve as pores that render high thermal and acoustic properties. Figure 7 schematically shows the experimental apparatus, where the test was carried on a Brüel \& Kjaer impedance tube 4206, with two microphones and amplifiers. This device permits the measurement of $\alpha$ for perpendicularly impacting waves. The impedance tube comprises a loudspeaker and two measuring microphones that are connected to the evaluation unit. Lengths of $X_{1}=0.15 \mathrm{~m}, X_{2}=0.1 \mathrm{~m}$, and $X v=10 \mathrm{~mm}$ reflect the actual thickness of tested sample.

As the measurement signal, pink noise was used. The socalled pink noise is a signal with a frequency spectrum such that the power spectral density (PSD, energy, or power per frequency interval) is proportionally inverse to the signal frequency [45]. In the pink noise, each octave (halving/doubling in frequency) carries an equal amount of noise energy. Noise records with various statistical characteristics, for example, uniform and Gaussian distributions, can be generated. However, generally, this noise exhibits a "white" spectrum, implying that the noise retains its statistical characteristic at all frequencies. With respect to power at a constant bandwidth, pink noise falls off at $3 \mathrm{~dB}$ per octave. The pink or typically socalled $1 / f$ noise is one of typical ambient noises in nature and transport or even could describe a flowing river and beating heart [46]. Gilden et al. have reported an unusual study where they described connection with human cognition [47]. That is, when a person attempts to remember, for example, a temporal interval, some errors are inevitably associated with the estimate. The sequences of errors in spatial and temporal replications were found to fluctuate as $1 / f$ noises. As reported by McClain [45], researchers often create $1 / f^{2}$ noise as a mistake instead of their required results. The generation of $1 / f$ noise involves amplitude scaling in the frequency domain by $1 / \sqrt{ } f$ and not just by $1 / f$ itself. Generally, the magnitude of acoustic variables depends on the frequency $f$. In actual cases in which frequency spectra would be measured with a step $d f=1 \mathrm{~Hz}$, their processing would be extremely complicated. In these cases, frequency bands with the percentually constant width are introduced. This condition is satisfied by octave or thirdoctave frequency bands.

Typically, ten octaves are characterised by $f_{2} / f_{1}=2$, where indexes 2 and 1 represent the higher and lower frequencies, respectively. Each octave is marked by the middle frequency $f_{\mathrm{m}}$ :

$$
f_{\mathrm{m}}=\sqrt{f_{1} \cdot f_{2}}
$$

The third-octave band is created by the octaves to their logarithmical thirds. Therefore, 30 bands are obtained.

The frequencies $f_{1}$ and $f_{4}$ border the one octave band and $f_{2}$ and $f_{3}$ indicate the frequencies of the inner thirds of the octave. Then, it is possible to claim that the log of inner frequencies ratio is equal to

$$
\log \frac{f_{2}}{f_{1}}+\log \frac{f_{3}}{f_{2}}+\log \frac{f_{4}}{f_{3}}=\log \frac{f_{4}}{f_{1}}=\log 2 .
$$

Based on (25), the ratio between any adjacent frequencies is constant.

$$
\frac{f_{2}}{f_{1}}=\frac{f_{3}}{f_{2}}=\frac{f_{4}}{f_{3}}=\sqrt[3]{2} .
$$

Finally, the dependence between two consecutive lying middle frequencies of the third-octave bands is

$$
f_{\mathrm{mi}} \cdot \sqrt[3]{2}=f_{\mathrm{mi}+1} .
$$

In our case, the third-octave bands were used to describe the acoustic absorption level.

During measurements, the actual distance between the microphones and sample must be considered relative to the speed of sound in the ambient medium, which was done on 
TABle 4: The created combinations of matrix (plaster), dispersion (fibres), and number of their picture below.

\begin{tabular}{llll}
\hline & Gypsum & Cement & Thermo UM \\
\hline Pure & Figure 5(a) & Figure 5(b) & Figure 5(c) \\
Glass & Figure 5(d) & Figure 5(e) & Figure 5(f) \\
Basalt & Figure 5(g) & Figure 5(h) & Figure 5(i) \\
\hline
\end{tabular}

the basis of $k$. The final $k$ factor is a complex number with the real part $k^{\prime}(27)$ and the imaginary part $k^{\prime \prime}(28)$ :

$$
\begin{gathered}
k^{\prime}=\frac{2 \pi f}{c}, \\
k^{\prime \prime}=0.194 \times \frac{f^{1 / 2}}{c^{0.635}} .
\end{gathered}
$$

Then, $H$ is equal to the multiplication of complex numbers $K$ and distance $x_{i}$. Based on those results and from the data measured on the two microphones at sampling ratios of $48 \mathrm{kHz}$ and 4097 complex samples, the final value of the absorption coefficient can be obtained. During operation, it is crucial to find the real and imaginary parts of reflection, transfer function $H_{12}$, phase shift $\varphi_{12}$, and their exponential shape $e^{j \varphi 12}$ and set the absorption coefficient $r_{i}$. Finally, the absorption coefficient $\eta$ is computed as (29) or in the same manner only using a different formula (8):

$$
\eta=1-\left(\operatorname{real} r_{i}^{2}+\operatorname{im} r_{i}^{2}\right) \text {. }
$$

\section{Results and Discussion}

The fundamental material properties of samples significantly affect sound absorption. In particular, one of the most important parameters is porosity. According to the FEM simulation, the best absorption should be observed for Thermo UM (Figure 8). Figures 8-10 show the model results obtained from the sound absorption shown at a frequency of $1000 \mathrm{~Hz}$. However, the model can be used at any frequency within the defined range. Based on the model results obtained in Figures 8-10, it is also possible to determine the effective thickness in which samples should be used. As can be observed for the cement sample (Figure 9), only $\sim 2 / 3$ of the thickness effectively shield, thereby decreasing absorption. Hence, the structure of the material does not use the entire sample thickness with a constant acoustic attenuation efficiency. With the possible improvement in the effective absorption thickness of the samples and internal material attenuation, the fibres were added into FEM. In the model simulation of the gypsum sample, the effect of glass and basalt fibres was examined. Clearly, fibres significantly affect the total absorption (Figure 10). Basalt fibres, not glass fibres, are extremely suitable for increasing the sound absorption at a high thickness. However, this statement cannot be generalised because it depends on the combination of the plaster and fibres used. With other plasters, better results can be achieved with glass fibres and worse results were observed with the basalt fibres (Figure 11). Probably, compared simply to the fundamental physical properties, the extent to which the added fibre reinforcement can increase the inner porosity of the material used is key. Hence, in this case, it is not possible to strictly rely only on model simulation, but it is necessary to conduct experiments with actual reinforced materials.

At the start of measurements, the repeatability of the main process and sample behaviour were verified. For the same samples, repeatable results were obtained, without any significant deviation from several sets of samples. However, the testing process was extremely sensitive to the actual sample shape (Figure 9). In case of a gap between the specimen and inner tube wall, measurement results were overestimated on account of the undiluted waves as well as the occurrence of vibrations from the imperfectly touching parts. Figure 12 shows the comparison of two ideal samples (dashed) and one nonideally circular sample number 3 (straight grey line). A comparison of the FEM model revealed similar results obtained from the measurements; however, Figure 13 shows a more uniform course. Figures 14-16 show the dependence of the acoustic absorption of each tested plaster material on the type of fibres used. The best acoustic absorption was achieved by the basalt-fibre-reinforced cement plaster. For better clarity, the results are also shown in the third-octave band in Figure 17.

In addition, the cement plaster with no fibre reinforcement exhibited the worst acoustic absorption. On the other hand, a lime-cement plaster with thermal insulating properties exhibited good acoustic absorption, even without fibre reinforcement, which was related to the nature of the inner mixture.

Dry plaster mixture contained hollow silicate beads, which positively affected the acoustic properties of the mixture and led to increased attenuation (Figure 14). However, by the addition of a fibrous dispersion into this mixture, the acoustic properties were degraded. On the other hand, the most significant increase in acoustic absorption occurred by the addition of fibres into the cement plaster, which was predicted after image analysis because in the basic material, the inner sample structure was clearly homogeneous with minimum pores. Therefore, it is not possible to state that the addition of a fibrous dispersion into plaster materials will generally improve their acoustic damping or favour a particular reinforcement that would be universal for all plasters. Randazzo et al. [14] have tested clay plasters, and their results revealed that the addition of natural fibres leads to increased open pores and subsequently improved acoustic absorption. With these results, it is possible to agree, but not generalise. Similar results were also reported by Neithalath et al. [20], who examined the effect of cellulose fibres on the acoustic absorption of cement composites. He found that the acoustic absorption coefficient increases with the volume of fibres in the composite. This viewpoint can be slightly misleading because with a high fibre content, the mechanical properties are degraded, and the effectiveness of the increased attenuation is not proportional. Bentchikou et al. [23], who examined the mechanical properties of the resultant cement composite by the addition of cellulosic fibres to cement, were aware of this issue. Their results, similar to those discussed herein, revealed that the addition of a high amount of fibres generally leads to the decrease in the 


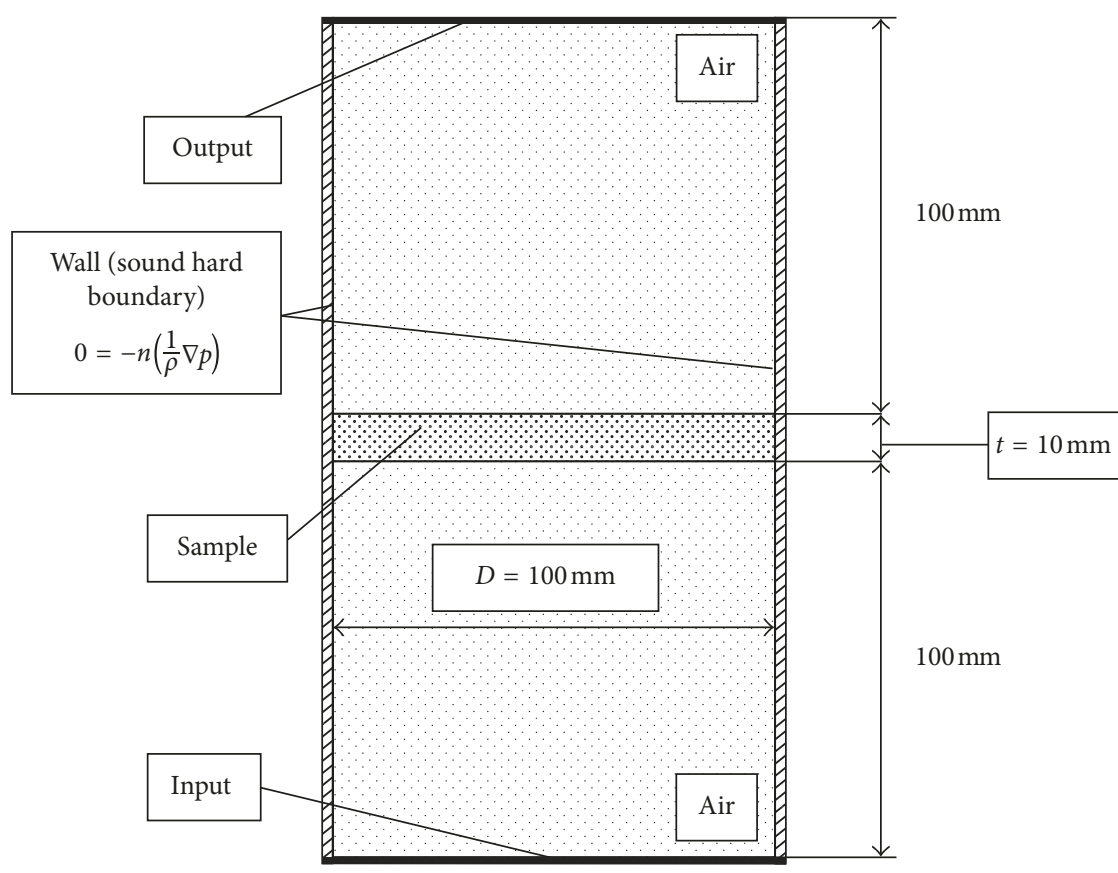

(a)

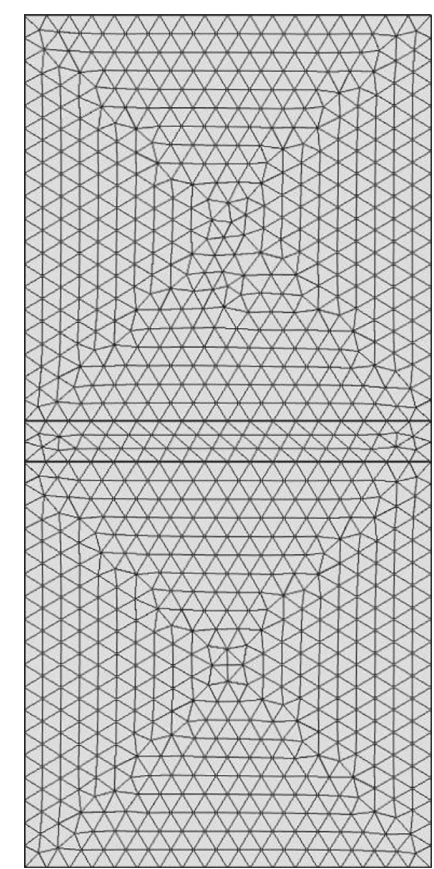

(b)

FIGURE 6: FEM model scheme and the mesh domain.

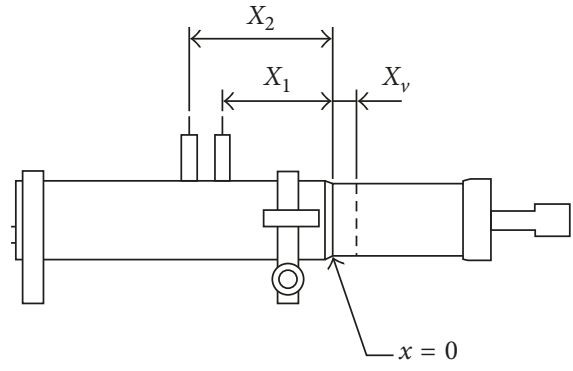

(a)

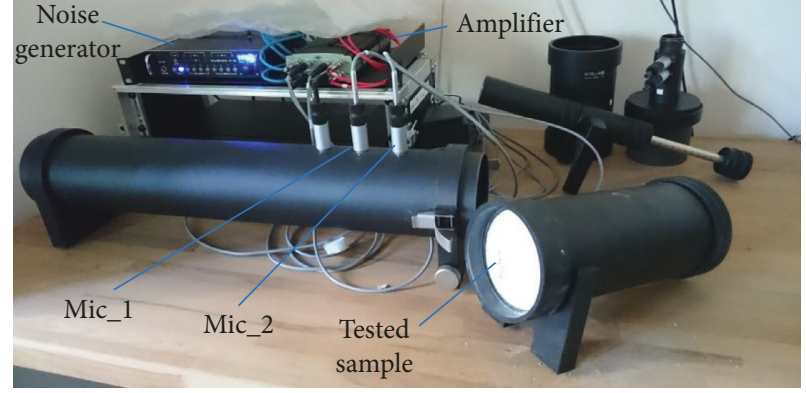

(b)

Figure 7: Experimental measurement (scheme and real device).

compressive and tensile strength. Hence, $1 \%$ of fibre reinforcement is examined to improve the acoustic properties and prevent the degradation of mechanical properties in the tested materials.

\section{Conclusion}

Modern science does not emphasise only on the improvement of technologies, materials and their properties, but also focuses on the environment as well as the protection and comfort of human health. Hence, the effect of natural fibre reinforcement on the acoustic absorption of plaster composites is investigated herein. After the initial study, typical plasters were selected for experimental and numerical studies to determine the possibilities observed by the effects of the addition of fibre reinforcement on their acoustics properties. Lime cement, cement, and gypsum plasters were selected not only for their physical properties but also for their typical use in the construction industry under geographical conditions. Plaster materials are disadvantageous because of their low tensile strength, which decreases the plaster life and causes visible defects and cracks. After previous studies reported by Samková et al. [17] on the amount of materials and fibres, glass and basalt fibres were added to the plasters as $1 \%$ by weight ratio of the fibrous reinforcement to improve the mechanical properties. The acoustic attenuation of plaster composites was not considerably affected by the mechanical properties of the fibres, but it was affected by final structure of the plaster mixture, especially the amount, size, and pore structure. Both fibres are typically used in the industry in different applications and forms, which is attributed to their good mechanical and physical properties, cost-effectiveness, and medical benign nature. Another important conclusion was the dependence 


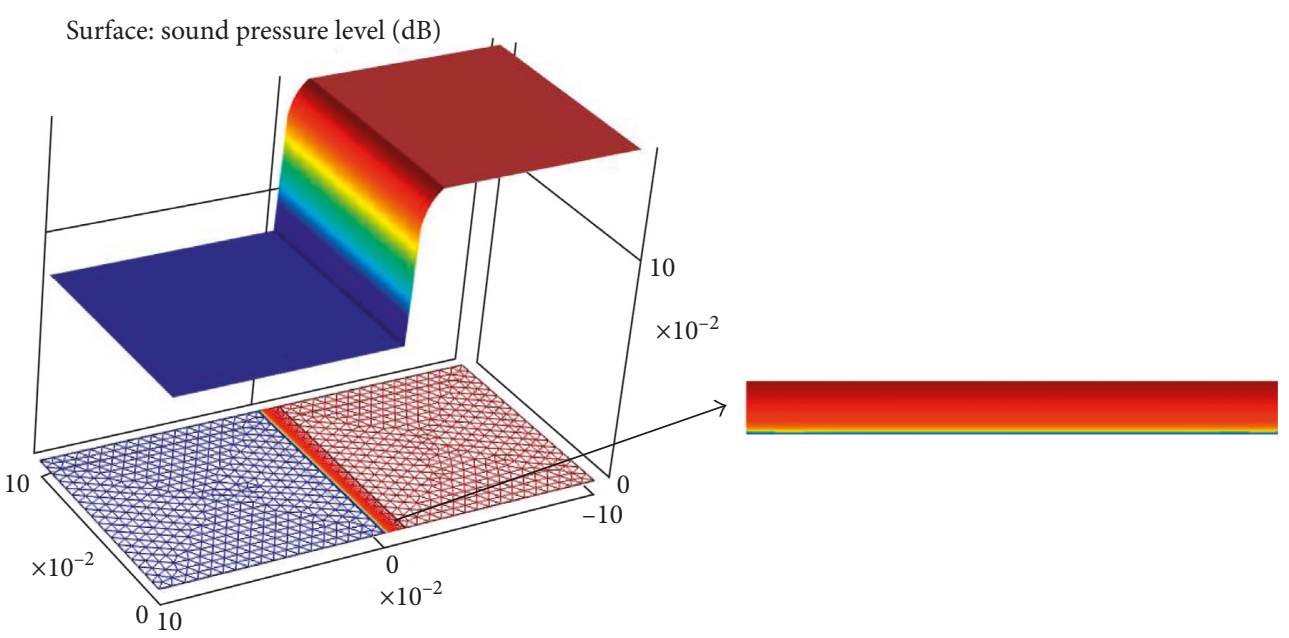

Min

A $\operatorname{Max}$

FIGURE 8: FEM model with the Thermo UM sample for investigating the minimum and maximum sample absorption.

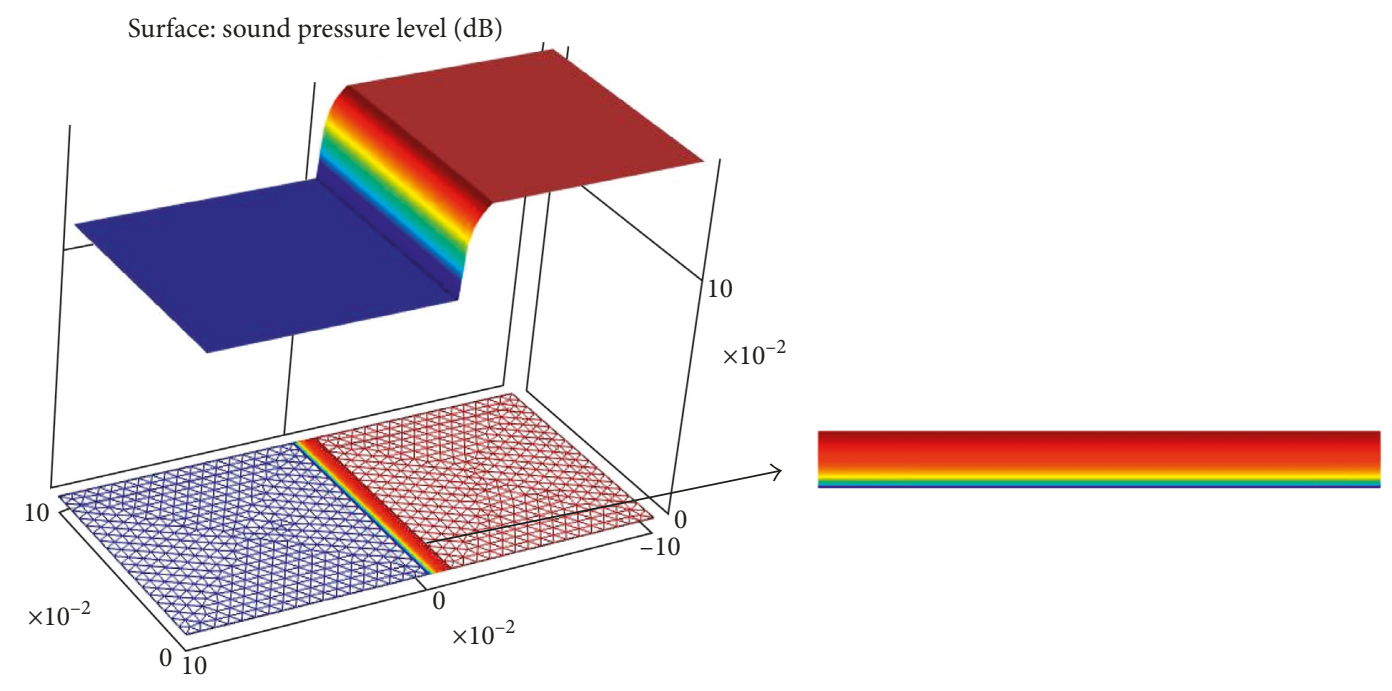

FIgURE 9: FEM model with the cement sample.


FIGURE 10: FEM model with the gypsum sample. 


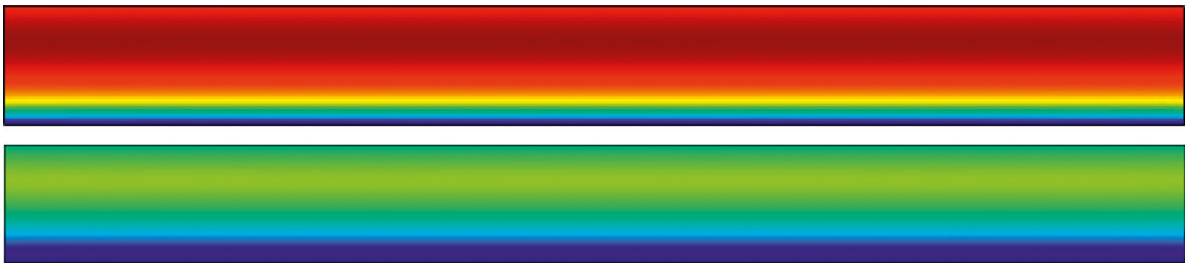

FIgURE 11: Comparison of the FEM model for gypsum with basalt fibre (upper) and gypsum with glass fibres (lower).

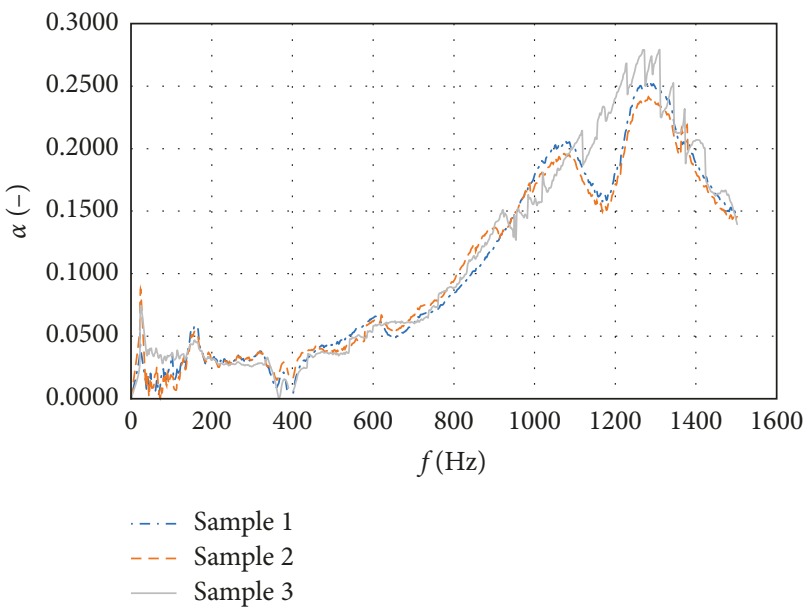

FIGURE 12: Experimental comparison of the cement plaster samples (sample 3 nonideal circularity).

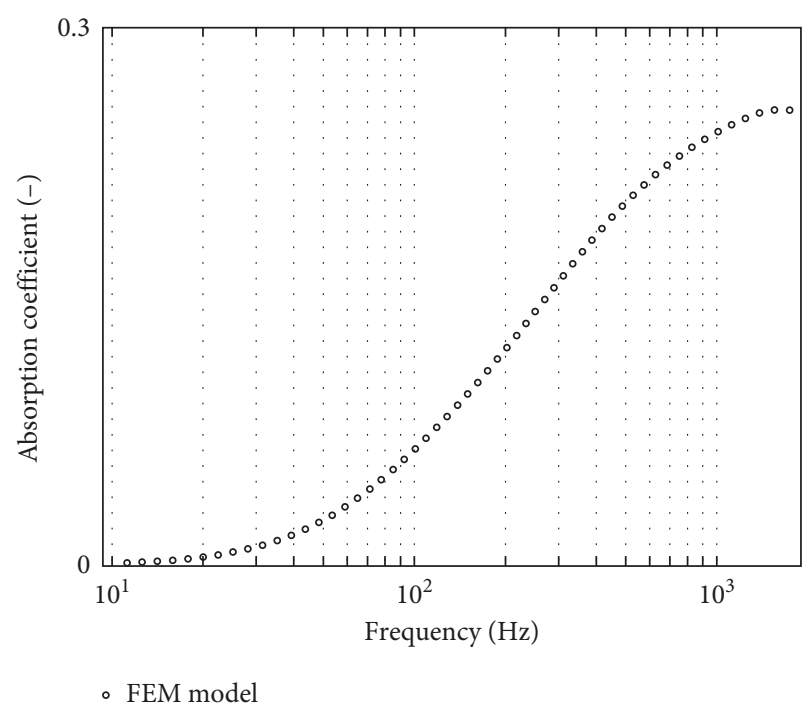

Figure 13: Numerical model for the attenuation in pure cement plaster.

of the effective attenuation on the material thickness in different plasters. That is, it is not true to generalise that the wider the plaster layer, the higher the acoustic attenuation will be proportionately (i.e., twice the layer thickness does not exhibit two times better absorption). Nevertheless, when the effective thickness is known, it is possible to combine the suitable fibre dispersion so as to achieve even better results with a significantly thin material layer, which could

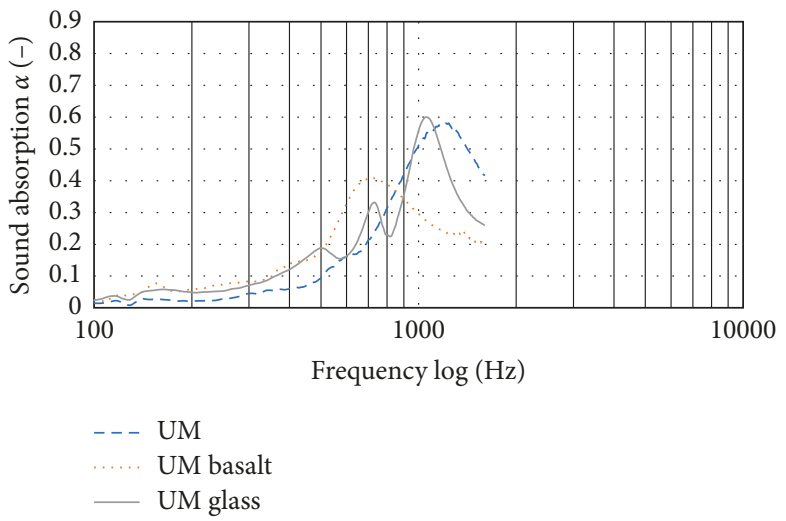

FIGURE 14: Obtained absorption coefficient values for the Thermo UM plaster.

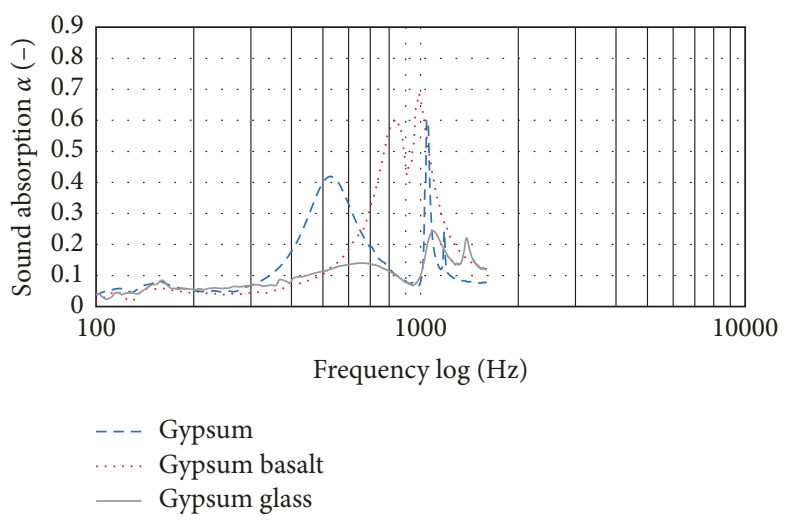

FIGURE 15: Absorption coefficient values obtained for gypsum.



FIGURE 16: Absorption coefficient values obtained for cement. 
UM



Frequency $(\mathrm{Hz})$

UM glass

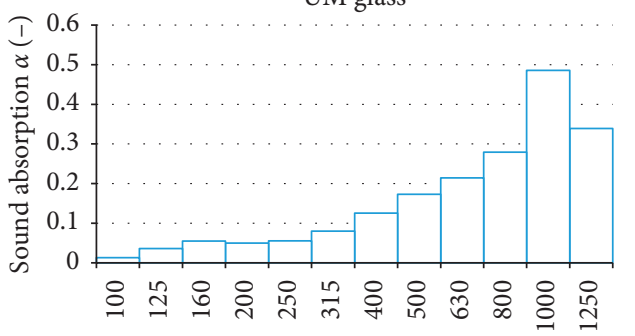

Frequency $(\mathrm{Hz})$

Gypsum basalt

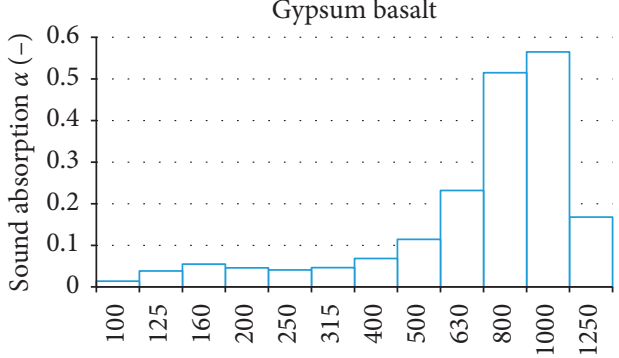

Frequency $(\mathrm{Hz})$

Cement

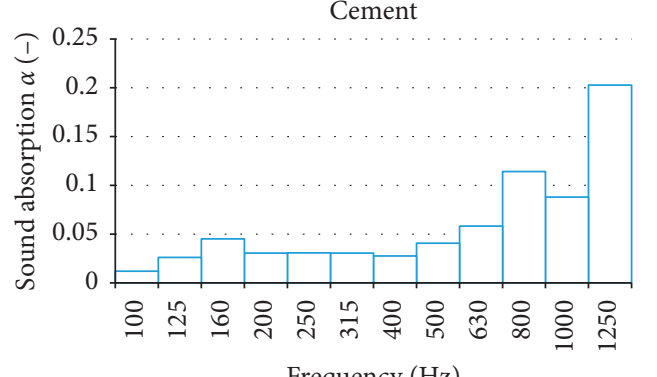

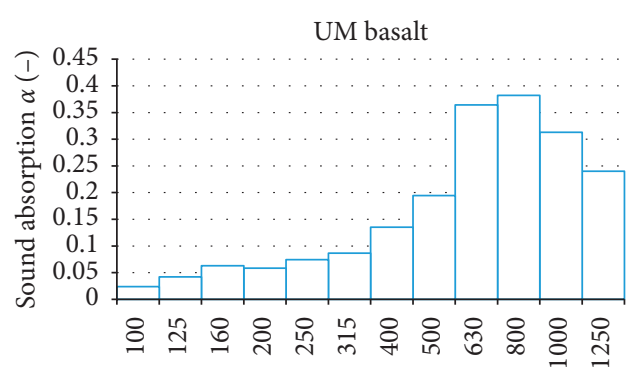

Frequency $(\mathrm{Hz})$

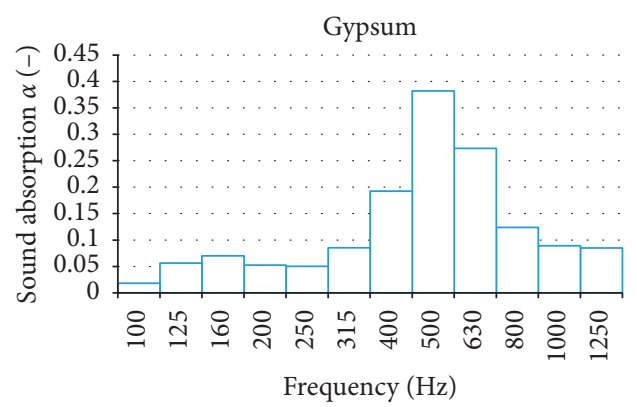

Gypsum glass

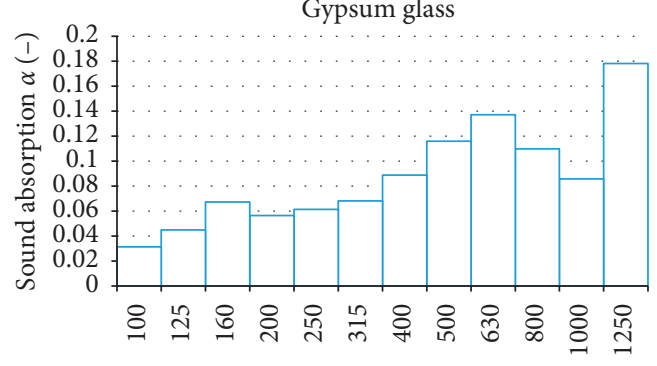

Frequency $(\mathrm{Hz})$

Cement basalt

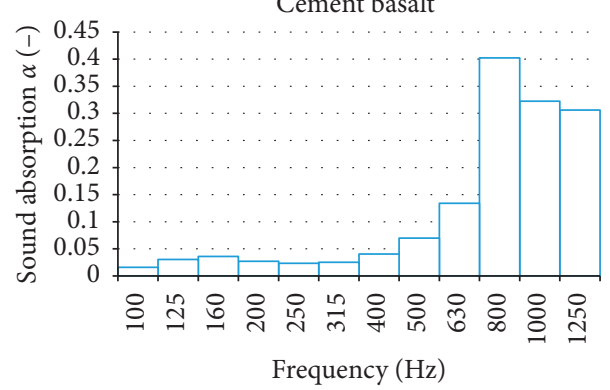

Cement glass

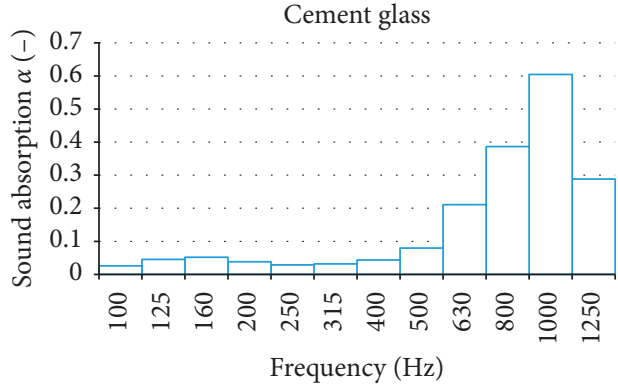

FIGURE 17: Comparison of the individual samples in the third-octave bands. 
considerably lead to material and cost savings. As part of our future work, we intend to improve the existing numerical models, especially material models for reinforced plasters, and to extend their applications to electromagnetic shielding.

\section{Conflicts of Interest}

The authors declare that they have no conflicts of interest.

\section{Acknowledgments}

This paper was written at the Technical University of Liberec as part of the results of the project LO1201 which were obtained with cofunding from the Ministry of Education, Youth and Sports as part of targeted support from the "Narodni program udrzitelnosti I" programme and the project Options Reinforcement Plaster Using Fibrous Materials (21195) with the support of the Specific University Research Grant provided by the Ministry of Education.

\section{References}

[1] P. Baltrenas, D. Butkus, R. Grubliauskas, and J. Kuciaukaite, "Noise studies and reduction possibilities in a residential area located by a highway," Ecology, vol. 55, no. 1, pp. 48-57, 2009.

[2] C. D. Francis, J. Paritsis, C. P. Ortega, and A. Cruz, "Landscape patterns of avian habitat use and nest success are affected by chronic gas well compressor noise," Landscape Ecology, vol. 26, no. 9, pp. 1269-1280, 2011.

[3] A. H. Chahrour and K. A. Soudki, "RBS polymer encased concrete wall. Part II: experimental study and theoretical provisions for combined axial compression and flexure," Construction Build Materials, vol. 20, no. 10, pp. 1016-1027, 2006.

[4] European Commission, Directive on Environmental Noise, 2002/49/CE, DOCE L 189, 7/18/02, European Commission, Brussels, Belgium, 2002.

[5] C. Diaz, A. Diaz, and M. A. Navacerrada, "An experimental study on the effect of rollong shutters on the field measurements of airborne sound insulation of facades," Applied Acoustic, vol. 74, no. 1, pp. 134-140, 2013.

[6] M. Frontczak and P. Wargocki, "Literature survey on how different factors influence human comfort in indoor environments," Building and Environment, vol. 46, no. 4, pp. 922-937, 2011.

[7] D. Cuiyun, C. Guang, X. Xinbang, and L. Peisheng, "Sound absorption characteristics of a high-temperature sintering porous ceramic material," Applied Acoustic, vol. 73, no. 865, p. 71, 2011.

[8] W. J. Cavanaugh, G. C. Tocci, and J. A Wilkes, Acoustics Architectural: Principles and Practice, Wiley, Hoboken, NY, USA, 2009.

[9] C. Bujoreanu, F. Nedeff, M. Benchea, and M. Agop, "Experimental and theoretical considerations on sound absorption performance of waste materials including the effect of backing plates," Applied Acoustics, vol. 119, pp. 88-93, 2016.

[10] M. A. Pedreño-Rojas, M. J. Morales-Conde, F. Pérez-Gálvez, and C. Rodríguez-Liñán, "Eco-efficient acoustic and thermal conditioning using false ceiling plates made from plaster and wood waste," Journal of Cleaner Production, vol. 166, pp. 690-705, 2017.
[11] M. K. Dixit, J. L. Fernández-Solís, S. Lavy, and C. H. Culp, "Identification of parameters for embodied energy measurement," Energy and Buildings, vol. 42, no. 8, pp. 1238-1247, 2010.

[12] J. Faustino, L. Pereira, S. Soares, D. Cruz, A. Paiva, and H. Varum, "Impact sound insulation technique using corn cob particleboard," Construction and Building Materials, vol. 37, pp. 153-159, 2012.

[13] T. Janusevicius, J. Mazuolis, and D. Butkus, "Sound reduction in samples of environmentally friendly building materials and their compositions," Applied Acoustic, vol. 113, pp. 132-136, 2016.

[14] L. Randazzo, G. Montana, A. Hein, A. Castiglia, G. Rodonò, and D. Donato, "Moisture absorption, thermal conductivity and noise mitigation of clay based plasters: the influence of mineralogical and textural characteristics," Applied Clay Science, vol. 132, pp. 498-507, 2016.

[15] L. Arnaud and E. Gourlay, "Experimental study of parameters influencing mechanical properties of hemp concretes," Construction and Building Materials, vol. 28, no. 1, pp. 50-56, 2012.

[16] P. Gle, L. Gourdon, and L. Arnaud, "Acoustical properties of material made of vegetable particles with several scales of porosity," Applied Acoustics, vol. 72, no. 5, pp. 249-259, 2011.

[17] A. Samková, P. Kulhavý, and M. Pechociaková, "Fibre reinforcement effect on plaster composite properties," in Proceedings of the NART Conference, pp. 189-195, Liberec, Czech Republic, August-September 2015.

[18] P. R. Blankenhorn, M. R. Silsbee, B. D. Blankenhorn, M. DiCola, and K. Kessler, "Temperature and moisture effects on selected properties of wood fiber-cement composites," Cement and Concrete Research, vol. 29, no. 5, pp. 737-741, 1999.

[19] P. Soroushian, S. Marikunte, and J. P. Won, "Statistical evaluation of mechanical and physical properties of cellulose fiber reinforced cement composites," Materials Journal, vol. 92, no. 2, pp. 172-180, 1995.

[20] N. Neithalath, J. Weiss, and J. Olek, "Acoustic performance and damping behavior of cellulose-cement composites," Cement and Concrete Composites, vol. 26, pp. 359-370, 2002.

[21] K. Kalinova, "A sound absorptive element comprising an acoustic resonance nanofibrous membrane," Recent Patents on Nanotechnology, vol. 9, no. 1, pp. 61-69, 2015.

[22] J. Mohrova and K. Kalinová, "Different structures of PVA nanofibrous membrane for sound absorption application," Journal of Nanomaterials, vol. 2012, Article ID 643043, 4 pages, 2012.

[23] M. Bentchikou, A. Guidoum, K. Scrivener, K. Silhadi, and S. Hanini, "Effect of recycled cellulose fibers on the properties of lightweight cement composite matrix," Construction and Building Materials, vol. 34, pp. 451-456, 2012.

[24] A. Izaguirre, J. Lanas, and J. Alvarez, "Effect of polypropylene fibre on the behavior of aerial lime-based mortars," Construction and Building Materials, vol. 25, no. 2, pp. 992-1000, 2011.

[25] A. Samková, P. Kulhavy, and M. Pechociaková, “Optimization parameters of plaster composites," in Proceedings of the 54th International conference on Experimental Stress Analysis, Srni, Czech Republic, May-June 2016, ISBN: 978-80-261-0624-1.

[26] D. A. Bies and C. H. Hansen, Engineering Noise ControlTheory and Practice, Spon Press, London, UK, 2009.

[27] J. Slavik, V. Stejskal, and V. Zeman, Fundamentals of Machine Dynamics, Czech University of Prague, Prague, Czech Republic, 1997. 
[28] N. Holmes, A. Browne, and C. Montague, "Acoustic properties of concrete panels with crumb rubber as a fine aggregate replacement," Construction and Building Materials, vol. 73, pp. 195-204, 2014.

[29] Z. Fišarova, Building Acoustics in Theory and Practice, Brno University of Technology, Brno, Czech Republic, 2014.

[30] E. Moretti, E. Belloni, and F. Agosti, "Innovative mineral fiber insulation panels for buildings: thermal and acoustic characterization," Applied Energy, vol. 169, pp. 421-432, 2016.

[31] C. N. Wang and J. H. Torng, "Experimental study of the absorption characteristics of some porous fibrous materials," Applied Acoustics, vol. 62, no. 4, pp. 447-459, 2001.

[32] Satsys Technology Ltd., Material Data Sheets of Plasters, Satsys Technology Ltd., Czech Republic, 2014.

[33] D. A. Kontogeorgos and M. A. Founti, "Gypsum board reaction kinetics at elevated temperatures," Thermochimica Acta, vol. 529, pp. 6-13, 2012.

[34] S. L Manzello, R. G. Gann, S. R. Kukuck, and B. L. David, "Influence of gypsum board type (X or C) on real fire performance of partition assemblies," Fire and Materials, vol. 31, pp. 425-442, 2007.

[35] P. Kulhavy, T. Martinec, O. Novak, M. Petru, and P. Srb, "Testing fireproof materials in a combustion chamber," EPJ Web of Conferences, vol. 143, p. 02058, 2017.

[36] G. B. Myron, Magmatic and Metamorphic Petrology, WilleyBlackwell, Hoboken, NY, USA, 2nd edition, 2002.

[37] J. Militky and V. Kovacic, "Basalt fibres a new prospectus of old material," Fiber and textile, vol. 7, no. 1, 2000.

[38] K. Singha, "A short review of basalt fiber," International Journal of Textile Science, vol. 1, no. 4, pp. 19-28, 2012.

[39] B. Wei, H. Cao, and S. Song, "Environmental resistance and mechanical performance of basalt and glass fiber," Material Science and Engineering: A, vol. 527, no. 18-19, pp. 4708-4715, 2010.

[40] Material database Matbase, Natural \& Synthetic Polymers, https://www.matbase.com/material-categories/natural-andsynthetic-polymers/.

[41] D. Das and B. Neckar, Theory of Structure and Mechanics of Fibrous Assemblies, WPI Publishing, New Delhi, India, 2012, ISBN: 978-1-84569-791-4.

[42] N. Kino and T. Ueno, "Comparison between characteristic lengths and fiber equivalent diameter in glass fiber and melamine foam materials of similar flow resistivity," Applied Acoustics, vol. 69, no. 4, p. 325, 2008.

[43] M. A. Biot, "The theory of propagation of elastic waves in a fluid-saturated porous solid. I. low-frequency range," Journal of the acoustical Society of America, vol. 28, no. 2, pp. 168-178, 1956.

[44] T. J. Cox and P. D. Antonio, Acoustic Absorbers and Diffusers, Theory, Design and Applications, Taylor and Francis, Abingdon, UK, 2nd edition, 2009.

[45] D. McClain, Numerical Simulation of Pink Noise, Vol. 1, The Rockefeller University, New York, NY, USA, 2001.

[46] P. Bak, C. Tang, and K. Wiesenfeld, "Self-organized criticality: an explanation of 1/f noise," Physical Review Letters, vol. 59, no. 4, pp. 381-384, 1987.

[47] D. L. Gilden, T. Thornton, and M. W. Mallon, " $1 / f$ noise in human cognition," Journal of Science, vol. 267, no. 5205, pp. 1837-1839, 1995. 


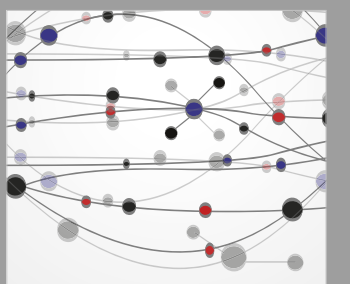

The Scientific World Journal


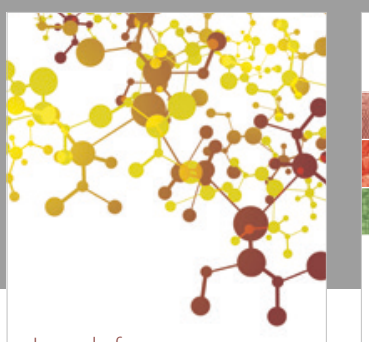

Journal of

Applied Chemistry
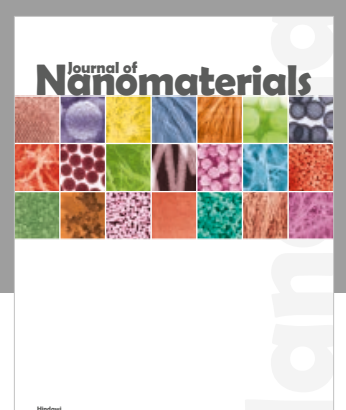

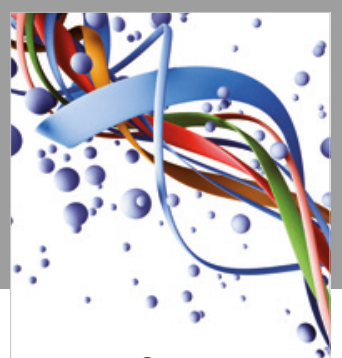

Scientifica



Polymer Science

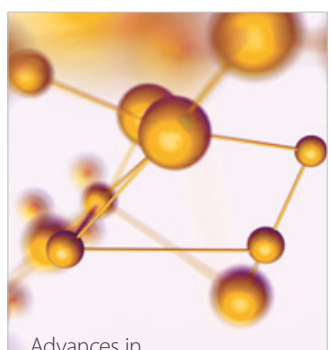

Physical Chemistry
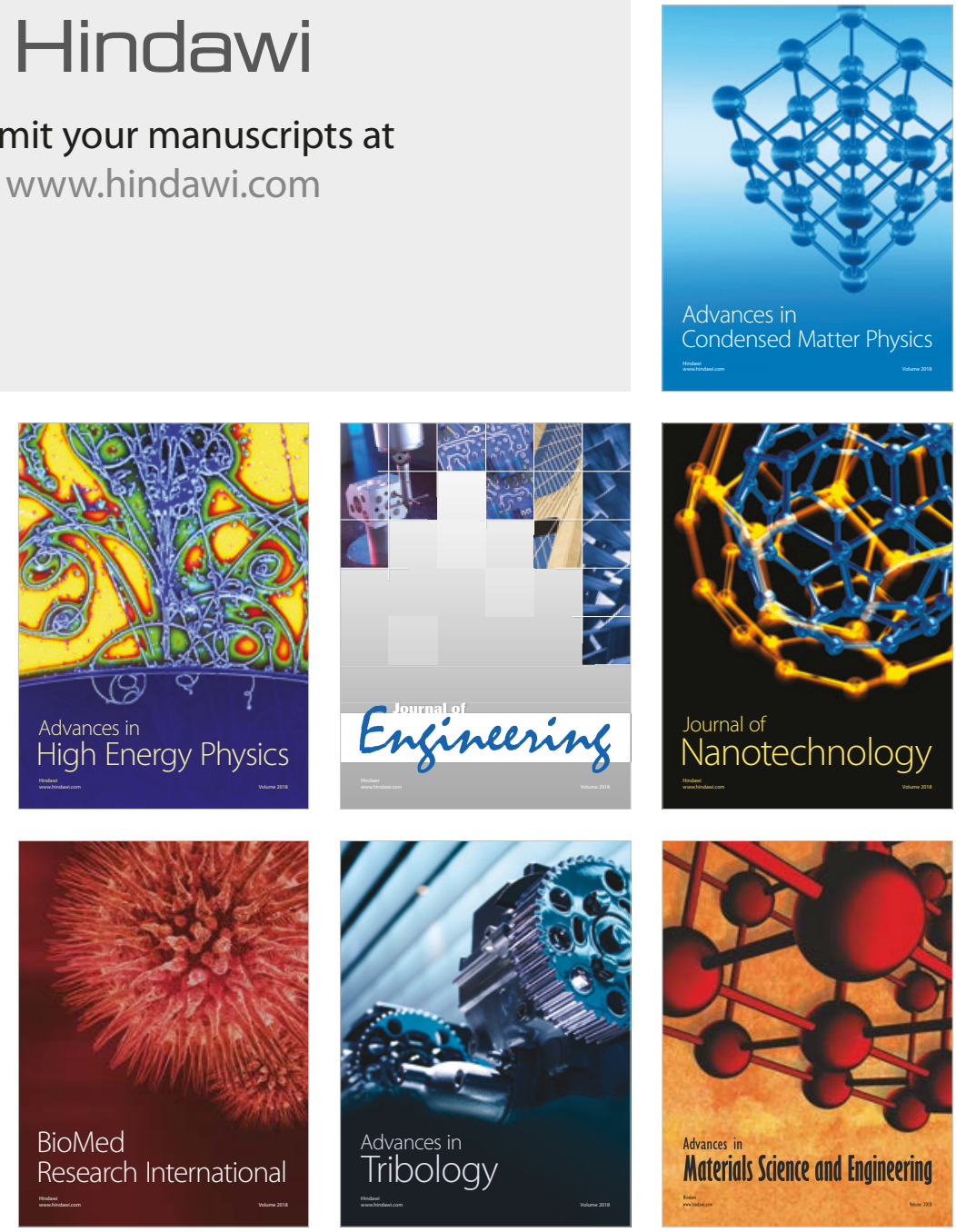